\title{
Dynamic Response and Its Frequency Domain Characteristics of Lateritic Soil Subgrade under Traffic Load during Construction
}

\author{
Wei Bai $\mathbb{D},{ }^{1}$ Kun Mu $\mathbb{D},{ }^{2}$ Lingwei Kong, ${ }^{1}$ Wenbo Zhang $\mathbb{D},{ }^{3}$ and Xiu Yue $\mathbb{D}{ }^{1,4}$ \\ ${ }^{1}$ State Key Laboratory of Geomechanics and Geotechnical Engineering, Institute of Rock and Soil Mechanics, \\ Chinese Academy of Sciences, Wuhan, Hubei 430071, China \\ ${ }^{2}$ Key Laboratory of Soft Soil Engineering Character and Engineering Environment of Tianjin, Tianjin Chengjian University, \\ Tianjin 300384, China \\ ${ }^{3}$ College of Water Resources and Architectural Engineering, Northwest Agriculture and Forestry University, Yangling, \\ Shaanxi 712100, China \\ ${ }^{4}$ University of Chinese Academy of Sciences, Beijing 100049, China
}

Correspondence should be addressed to Wei Bai; william_bai@yeah.net

Received 19 August 2020; Revised 19 September 2020; Accepted 12 October 2020; Published 24 October 2020

Academic Editor: Qiang Tang

Copyright (C) 2020 Wei Bai et al. This is an open access article distributed under the Creative Commons Attribution License, which permits unrestricted use, distribution, and reproduction in any medium, provided the original work is properly cited.

\begin{abstract}
Field tests were carried out on the compacted lateritic soil subgrade of Laibin-Mashan expressway in Guangxi Province to obtain the vertical vibration acceleration and dynamic stress amplitude of each test point under different axle loads and different driving speeds. The distribution law of the dynamic response and its frequency domain characteristics obtained by wavelet analysis emerged. The vibration of the subgrade is clearly aggravated by the increase of speed and load. Specifically, the acceleration of vehicle speed from $20 \mathrm{~km} / \mathrm{h}$ to $40 \mathrm{~km} / \mathrm{h}$ has a prominent effect on the vibration of subgrade, and the influence of speed on the vibration of subgrade decreases with subgrade depth. The acceleration has the greatest impact on the vibration energy in the third and fourth frequency bands.
\end{abstract}

\section{Introduction}

As an important part of the expressway, the subgrade bears the dynamic traffic loads during construction, which is characterized by heavy vehicle loads, high frequency of vehicle traffic, and varying speed between $20 \mathrm{~km} / \mathrm{h}$ and $60 \mathrm{~km} / \mathrm{h}$. During this period, dynamic deformation, cumulative settlement of subgrade, and even uneven settlement often occur. Therefore, studying the influence of vehicle load and speed on the dynamic response and its frequency domain characteristics of the subgrade is important [1]. Present research methods of the aforementioned issue can be divided into theoretical and numerical simulation methods [2-5] and in situ testing methods [6-8]. The former simplify vehicle load into moving a constant load, harmonic load, and random load; adopt concentrated load, rectangular uniform load, and other forms of load distribution; assume the subgrade and site as elastic or layered elastic space; and study the dynamic response of subgrade by using analytical method and numerical analysis method [9].

In contrast, in situ testing methods collect in situ test data by burying sensors and field measurement and then determine the law of the internal dynamic Earth pressure and vibration acceleration change with time and space. Compared with theoretical calculation and numerical simulation, in situ test has higher pertinence and intuitive data, which is the most direct and effective means to study the dynamic characteristics of subgrade [10]. Hyodo and Yasuhara [11] directed constant-weight heavy-duty trucks to go back and forth at different speeds and collected test data. They thought that the vertical Earth pressure of subgrade at different depths could be represented by the half-sinusoidal loading curve. Moreover, the relationship between the time of continuous pressure and speed was obtained. Xuan et al. [12] ordered heavy vehicles to act on the subgrade of the new expressway with different loads and different speeds to 
explore the corresponding dynamic response law. They found that dynamic stress is attenuated with the increase of depth, but its attenuating amplitude is closely related to speed and load. McEwen et al. [13] set up multiple test segments. In each test section, the dynamic response of the subgrade under the action of heavy-duty vehicles was measured by combining the influence of temperature, humidity, and other factors. Yu et al. [14] carried out field cyclic excitation tests under different working conditions and analyzed the dynamic response characteristics and accumulated deformation law of the cement-improved expansive soil subgrade under different axle load, train speed, natural, and water immersion conditions. Junhua et al. [15] directed field tests of cyclic loading for railway subgrade with different ground stiffness of fill sections and different forms of fill and cut sections. The experimental results showed that when fill sections were relatively high, the ground stiffness showed insignificant influence on the dynamic responses of railway subgrade. Through field tests and mathematical modeling, Connolly et al. [16] concluded that when the vehicle speed was low, the material properties of the soil were the most important factors affecting the dynamic response. Ribeiro et al. [17] carried out on-site dynamic tests to monitor the dynamic response indexes such as the dynamic displacement and the sleeper acceleration of the track in different sections for the passage of the trains at a speed of $220 \mathrm{~km} / \mathrm{h}$ and found that the displacements of the track on the structure and the transition wedge were lower than those of the track on the embankment. Connolly et al. [18] conducted three different types of trains and tested the dynamic response in three directions. It is found that, contrary to commonly accepted theory, vertical vibrations are not always the most dominant and that horizontal vibration should also be considered, particularly at larger offsets.

Lateritic soil is widely distributed in South China due to its hot and humid climate. Its particles are fine and uniform, with a high content of clay particles, and its high water content, liquid limit, plastic limit, and void ratio have a great impact on the stability of subgrade $[19,20]$. The existing research on the dynamics of lateritic soil subgrade is insufficient. Most of the studies focus on the dynamic response of the railway subgrade, and there are also studies on the dynamic response of highway subgrade, but only after the pavement is completed. [21, 22]. The superposition effect of subgrade dynamic response under traffic load during construction is not sufficiently studied, and the frequency domain features are not combined, which is exactly the key to reflecting the nonstationary signal of subgrade. Therefore, more scientific and comprehensive methods are needed to study the dynamic response and its frequency domain characteristics of lateritic soil subgrade under traffic loads during construction.

Based on practical engineering, this paper quantitatively analyzed the internal dynamic response of lateritic soil subgrade under the action of vehicles with different axial loads and speeds. By means of field dynamic stress monitoring and wavelet analysis, the frequency domain characteristics of the dynamic response of the subgrade were studied. The preceding work has momentous guiding significance for the design and construction of highway subgrade in lateritic soil areas.

\section{In Situ Test}

The monitored section selected from the lateritic soil fill embankment is located at K285 + 200 of Laibin to Mashan expressway in Guangxi, with a slope of $1: 1.5$. The liquid limit of the lateritic soil filler is $60.6 \%-68.2 \%$, the plastic limit is $22.5 \%-29.8 \%$, the specific gravity of the particles is 2.72 , and the moisture content is approximately $21.2 \%$.

2.1. Test Scheme. The influence of vehicle axle load and speed was mainly considered in the test scheme, including four different uniaxial loads and three different speeds. Based on this premise, 12 combinations of an operating condition at different levels were designed for testing. Table 1 lists these conditions.

2.2. Test Equipment. Strain Earth pressure box and piezoelectric accelerometer were used to measure the dynamic stress and acceleration corresponding to different depths of subgrade under dynamic load. The detailed parameters of the soil pressure box, shown in Figure 1(a), are as follows: measurement range: $0.002-1.5 \mathrm{MPa}$; nonlinear error: $\leq 0.5 \%$ FS; repeatability error: $\leq 0.5 \% \mathrm{FS}$; lag error: $\leq 0.5 \% \mathrm{FS}$; degree of insularity: $>300 \mathrm{M} \Omega$. Similarly, the specific parameters of the piezoelectric accelerometer, shown in Figure 1(b), are as follows: maximum allowable acceleration: $100 \mathrm{~m} / \mathrm{s}^{2}$; maximum lateral sensitivity ratio: $<5 \%$; working temperature: $40-120^{\circ} \mathrm{C}$; working current: $2-10 \mathrm{~mA}$; working voltage: $12-24 \mathrm{~V}$; frequency range: $0.2-2,000 \mathrm{~Hz}$; quality: $90 \mathrm{~g}$; diameter of circular section: $30 \mathrm{~mm}$. The specific parameters of the data acquisition system, shown in Figure 1(c), are as follows: dynamic range: $120 \mathrm{~dB}$; maximum sampling frequency: $5.12 \mathrm{kHz}$; measurement resolution: $0.1 \mu \varepsilon$; input voltage range: $\pm 5 \mathrm{~V}$; input strain range: $0- \pm 240,000 \mu \varepsilon$.

2.3. Sensor Setting. Figure 2 shows that the sensors were mainly buried within the vertical range $(0-400 \mathrm{~cm})$ below the temporary lane (width: $375 \mathrm{~cm}$ ). On the horizontal lines, $10 \mathrm{~cm}, 50 \mathrm{~cm}, 100 \mathrm{~cm}, 220 \mathrm{~cm}$, and $350 \mathrm{~cm}$ away from the top surface of the roadbed, the Earth pressure cells, temperature and humidity sensors, and accelerometers were buried successively from the road shoulder to the lane direction. According to the actual wheel spacing, the stress and accelerometer column distance is $200 \mathrm{~cm}$ to ensure that the sensor is located directly below the wheel track. Figure 2 shows the schematic of the in situ test equipment.

Owing to the interference of construction, the sensors were embedded by combining the hole drilling method and the layer-by-layer embedding method. Sensors with a buried depth of more than $50 \mathrm{~cm}$ were treated by hole drilling (Figure 3), and sensors at other positions were buried layer by layer (Figure 4 ). The hole drilling method required that the contractive cavity and collapse should be checked and 
TABLE 1: Test scheme.

\begin{tabular}{lcr}
\hline Condition number & Uniaxial load $(\mathrm{kN})$ & Vehicle speed $(\mathrm{km} / \mathrm{h})$ \\
\hline$\# 1 \# 3$ & 60 & $20,40,60$ \\
$\# 4-\# 6$ & 100 & $20,40,60$ \\
$\# 7-\# 9$ & 150 & $20,40,60$ \\
$\# 10-\# 12$ & 190 & $20,40,60$ \\
\hline
\end{tabular}

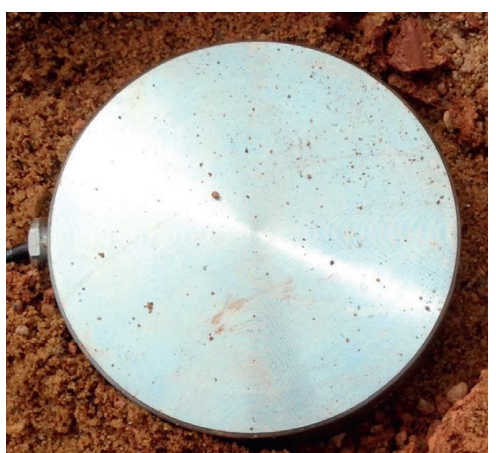

(a)

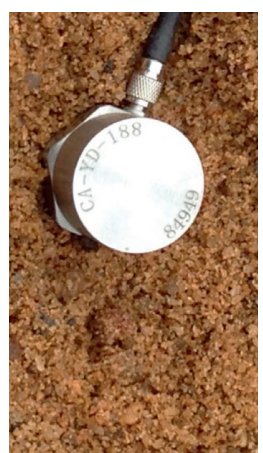

(b)

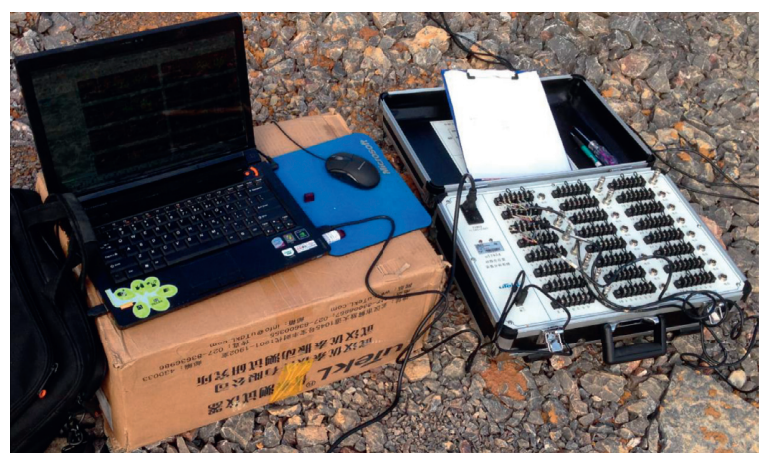

(c)

FIgURE 1: Sensor and data acquisition system: (a) strain Earth pressure cell, (b) accelerometer, (c) data acquisition system.
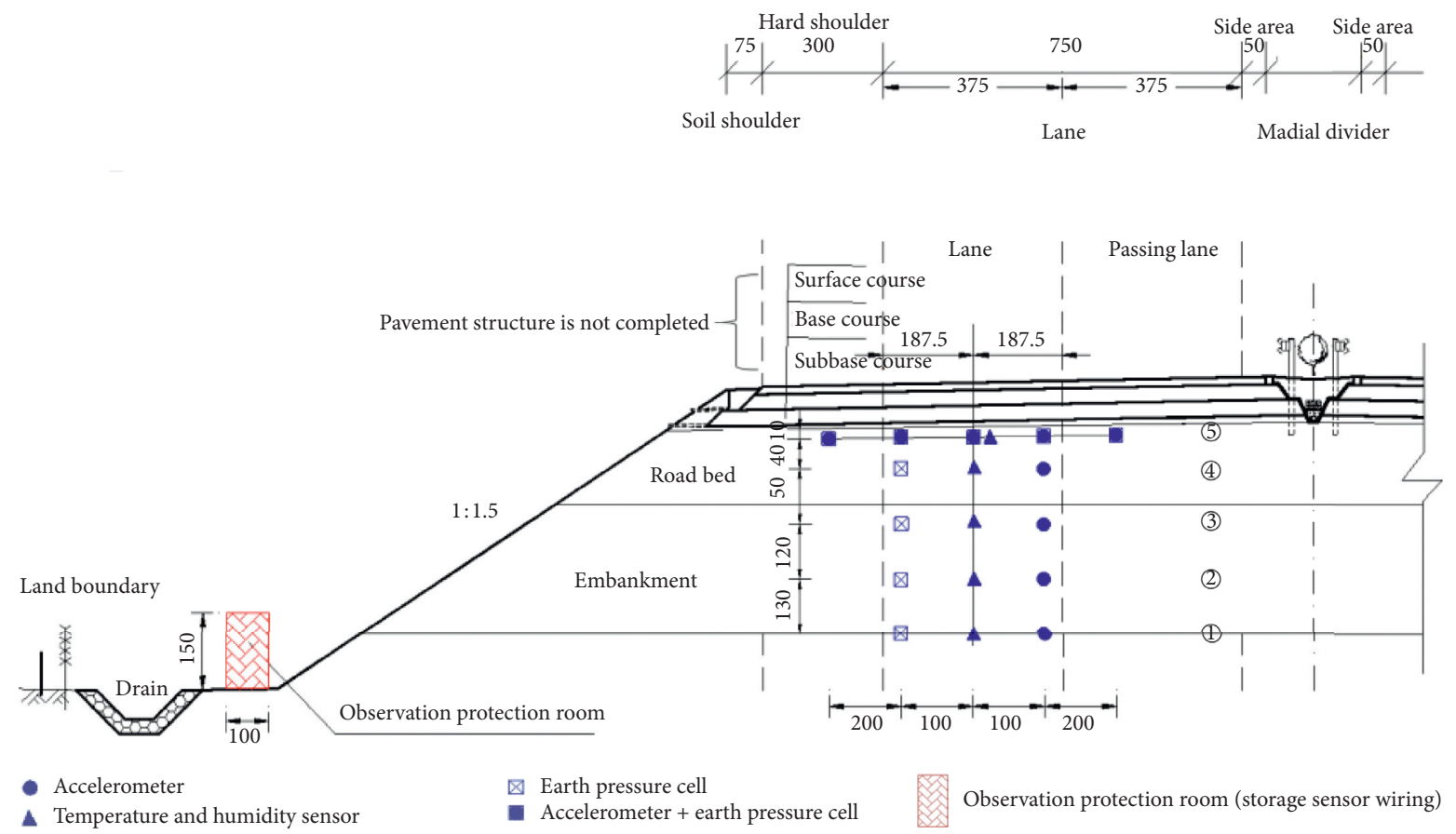

FIgURE 2: Schematic of the field sensor layout.

qualified after the hole was formed and before the burying of sensors and backfilling. Under the designed depth of each sensor, $10 \mathrm{~cm}$ thick fine sand shall be laid first, and then the sensor shall slowly be placed on the top surface of the sand layer along with the borehole using a string (triangular binding) to ensure that the contact surface was parallel to the top surface of the roadbed, as shown in Figure 3(c). The sensor would need to be covered with $10 \mathrm{~cm}$ thick fine sand to protect it. After the embedding of the sensors using the hole drilling method was completed, for every $40 \mathrm{~cm}$ of thick roadbed filled, a $20 \mathrm{~cm}$ deep trench should be excavated accordingly. Then, sand was laid, sensors were placed, and excavation was backfilled as described anteriorly for the layer-by-layer method. The filler was obtained by sieving the 


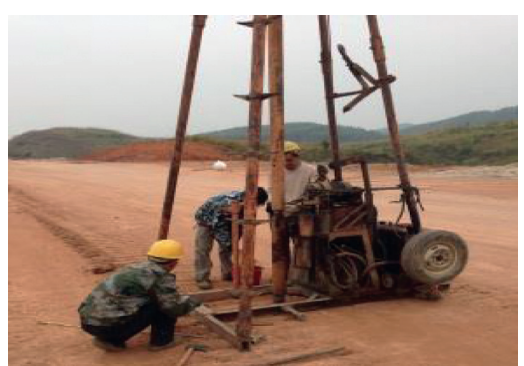

(a)

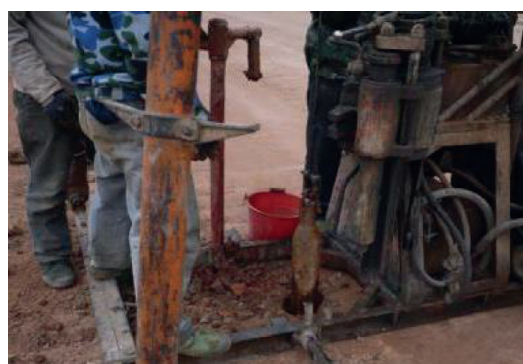

(b)

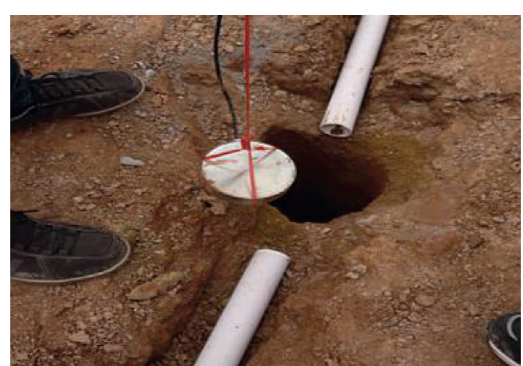

(c)

FIGURE 3: Drilling holes for embedding sensors onsite: (a) equipment being in place, (b) impact hole, and (c) placement sensor.

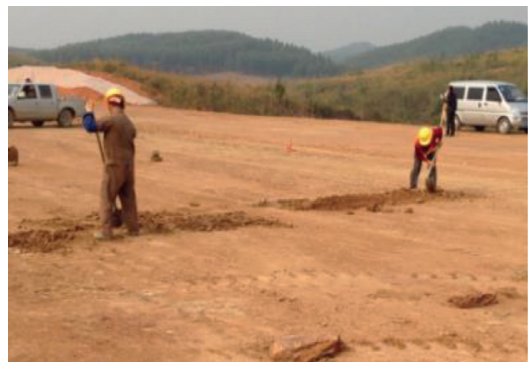

(a)

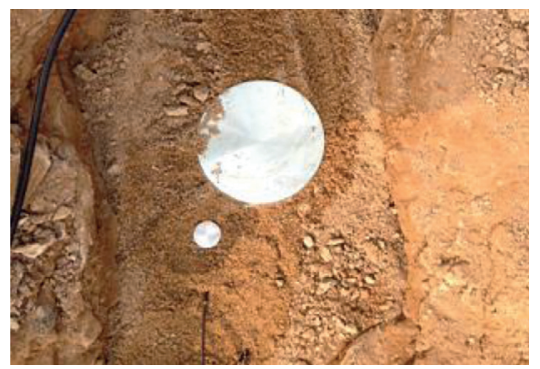

(b)

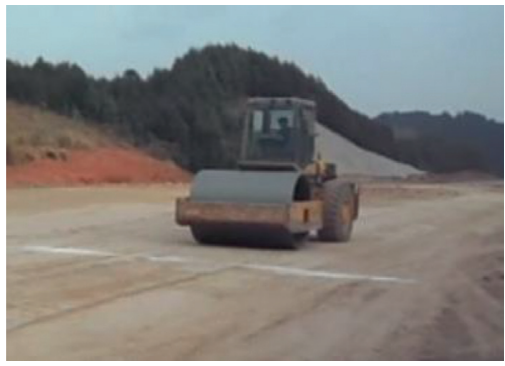

(c)

FIGURE 4: Implementation process of burying sensors layer by layer: (a) excavation groove, (b) embedding of sensors, and (c) compaction of the top surface of the roadbed.

same soil as the surrounding subgrade to ensure that no large void was present. In addition, the soil was compacted to ensure the same compactness as the surrounding roadbed.

2.4. Testing Process. As illustrated in Figure 5 for the preparation and testing process, the locations of sensors were accurately marked with bright colors. Vehicles with different axle loads drove on the road above the sensors at different required speeds.

\section{Test Results Analysis}

Figure 6 presents the typical time-history curves of dynamic stress and acceleration derived from in situ tests.

As illustrated in Figure 6(a), there are three clear peaks in the dynamic stress curve at a depth of $10 \mathrm{~cm}$, which far exceeds the peak values of the curve corresponding to a depth of $50 \mathrm{~cm}$, and the maximum peak value reaches $431.1 \mathrm{kPa}$. Curves drawn for other depths do not show significant peaks. On the whole, the dynamic stress decays with the increase of depth. The dynamic stresses are already quite small at $100 \mathrm{~cm}$ and are attenuated to $0 \mathrm{kPa}$ at $220 \mathrm{~cm}$. It can be found from Figure 6(b) that the vibration acceleration caused by vehicle loads presents the same law as the dynamic stress. In addition, with the depth from $10 \mathrm{~cm}$ to $50 \mathrm{~cm}$, the vibration acceleration is significantly attenuated, with an attenuation rate approaching $40 \%$.
Figure 7 shows the development of the peak dynamic stress and acceleration in the subgrade with speed under different axle loads.

As shown in Figure 7, the additional stress and vibration acceleration caused by vehicles with different speeds and loads passing through the test section decrease with the increase of depth. The additional stress is attenuated significantly from $10 \mathrm{~cm}$ to $50 \mathrm{~cm}$ away from the top of the roadbed, with a decay rate of nearly $40 \%$, and the decay rate reaches more than $90 \%$ at a depth of $100 \mathrm{~cm}$.

Observing preceding acceleration time-history curves reveals that speed has a great influence on peak acceleration. With the increase of vehicle speed from $40 \mathrm{~km} / \mathrm{h}$ to $60 \mathrm{~km} / \mathrm{h}$ with the axle weight of $19 \mathrm{t}$, the peak acceleration at $50 \mathrm{~cm}$ away from the roadbed surface correspondingly increases from $1.5 \mathrm{~m} / \mathrm{s}^{2}$ to $2.5 \mathrm{~m} / \mathrm{s}^{2}$. The variation trends of peak acceleration with speed are consistent under different axle loads. However, under the same driving speed, the peak acceleration increases with the increase of the load.

For different depths, the peak dynamic stress and acceleration evolve differently with speed. In particular, nonlinear relation is presented in the surface layer of the subgrade, whereas linear relation is presented in the deep layer, especially for acceleration. Major differences are observed in the critical depth corresponding to the abovementioned relationship from nonlinear to linear, for dynamic stress and acceleration. The critical depth of nonlinear relation (less than $50 \mathrm{~cm}$ ) is less than that of linear relation (about $100 \mathrm{~cm}$ ). 


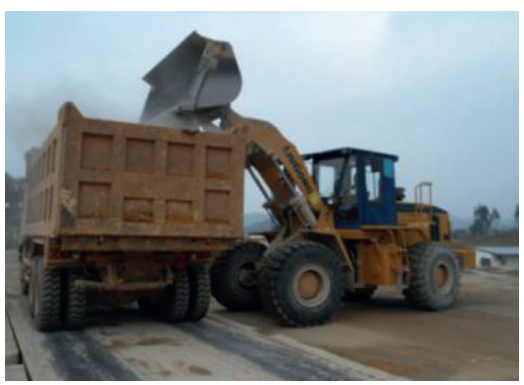

(a)

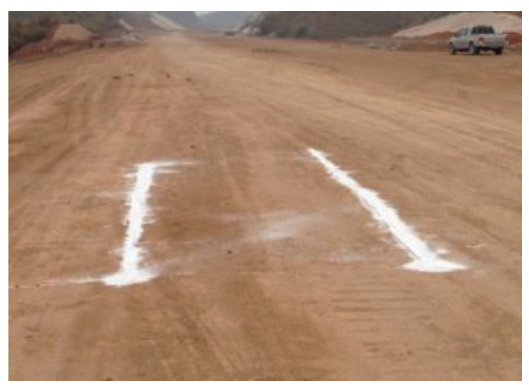

(b)

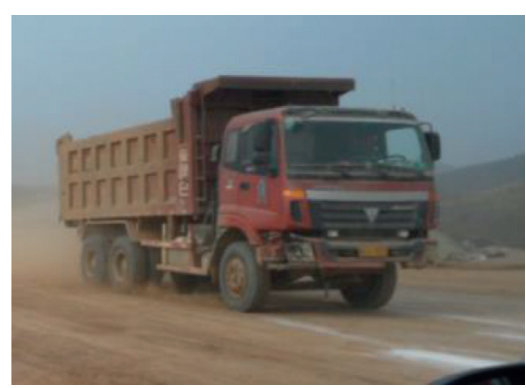

(c)

FIGURe 5: Preparation and testing process: (a) truck rear axle weighing, (b) marked position of the sensor, and (c) the truck passing over the sensor.

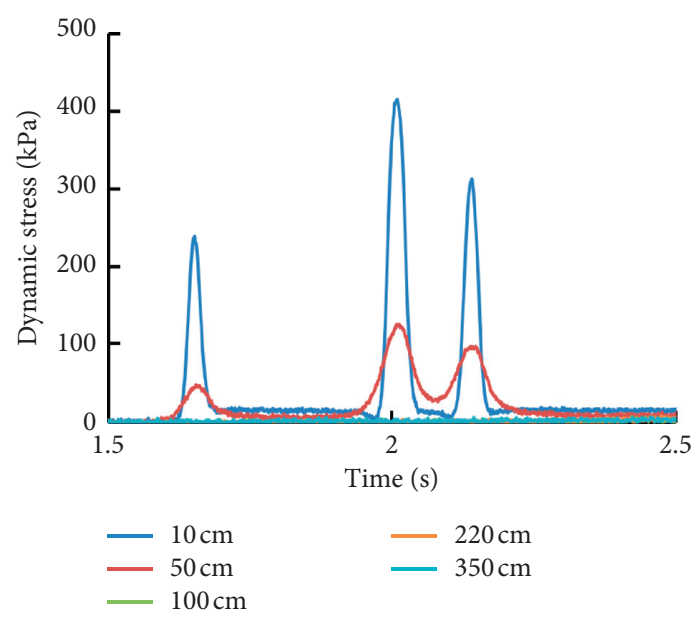

(a)

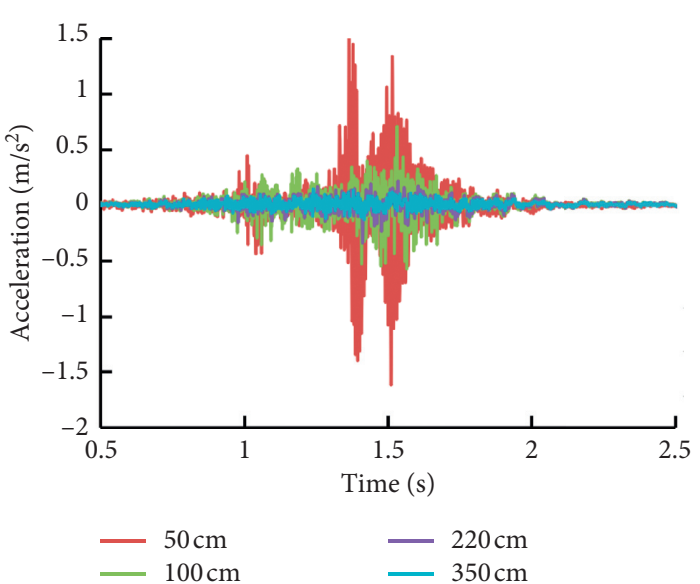

(b)

FIGURE 6: Typical time-history curves of dynamic stress and acceleration: (a) dynamic stress time-history curve, and (b) acceleration timehistory curve.

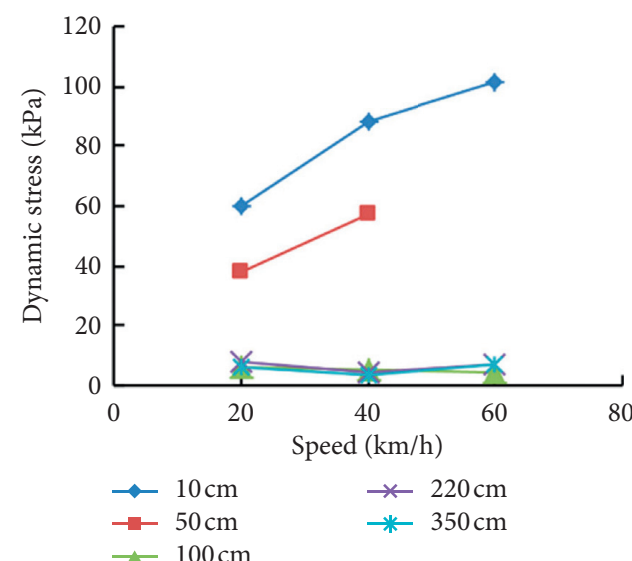

(a)

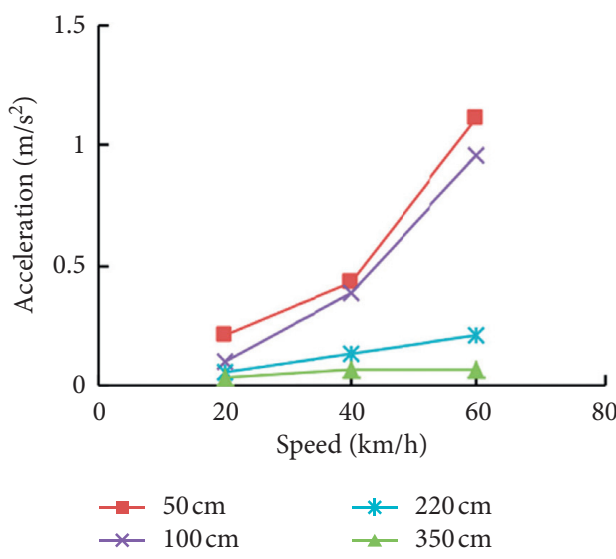

(b)

FIgURe 7: Continued. 


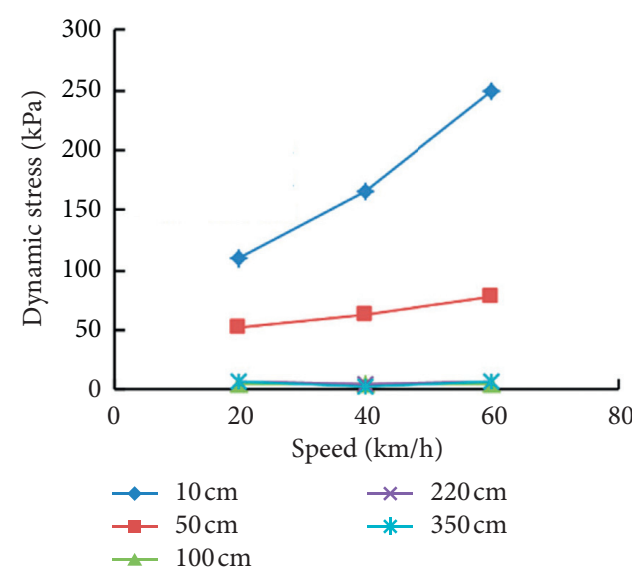

(c)

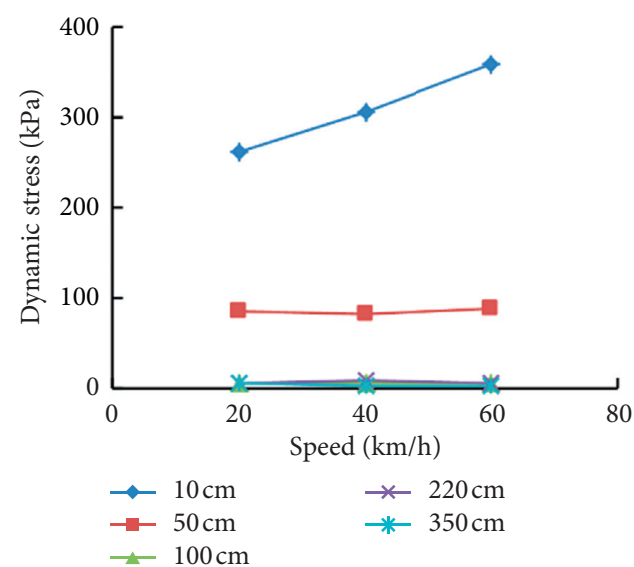

(e)

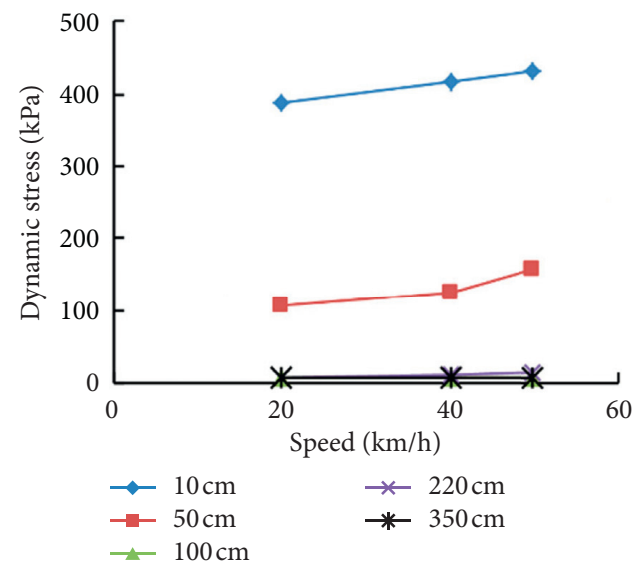

(g)

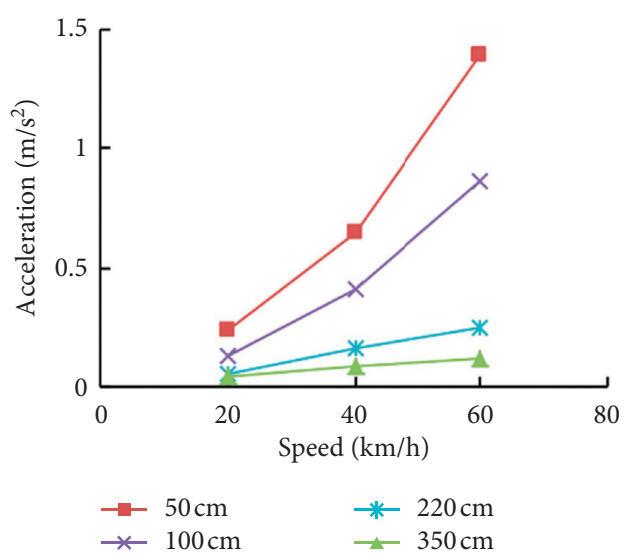

(d)

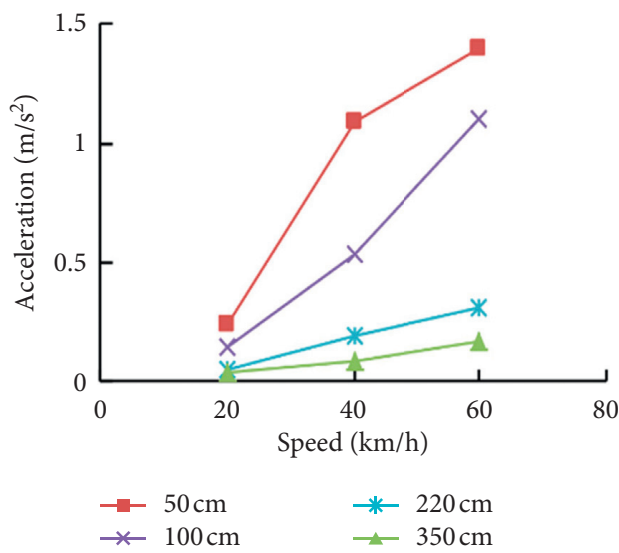

(f)

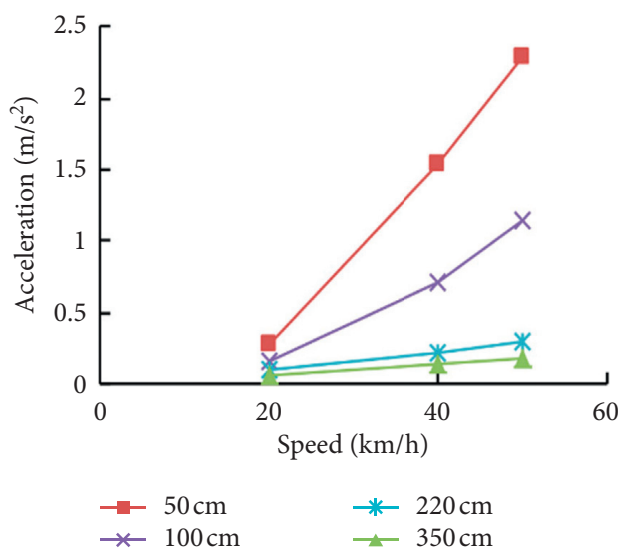

(h)

FiguRE 7: Development of peak dynamic stress and acceleration with vehicle speed under different axle loads: (a) dynamic stress of subgrade at $6 \mathrm{t}$ axial weight, (b) acceleration of subgrade at $6 \mathrm{t}$ axial weight, (c) dynamic stress of subgrade at $10 \mathrm{t}$ axial weight, (d) acceleration of subgrade at $10 \mathrm{t}$ axial weight, (e) dynamic stress of subgrade at $15 \mathrm{t}$ axial weight, (f) acceleration of subgrade at $15 \mathrm{t}$ axial weight, (g) dynamic stress of subgrade at $19 \mathrm{t}$ axial weight, and (h) acceleration of subgrade at $19 \mathrm{t}$ axial weight.

\section{Frequency Domain Analysis of Subgrade Vibration}

The amplitude of vibration response only reflects the statistical laws of peak values of time-history curves. To understand the vibration characteristics of the subgrade, an in-depth analysis of the frequency domain is necessary. Taking the signal of a certain measuring point as an example for frequency domain analysis, Figure 8 shows the power spectral density curve. More peaks in the curve mean that 


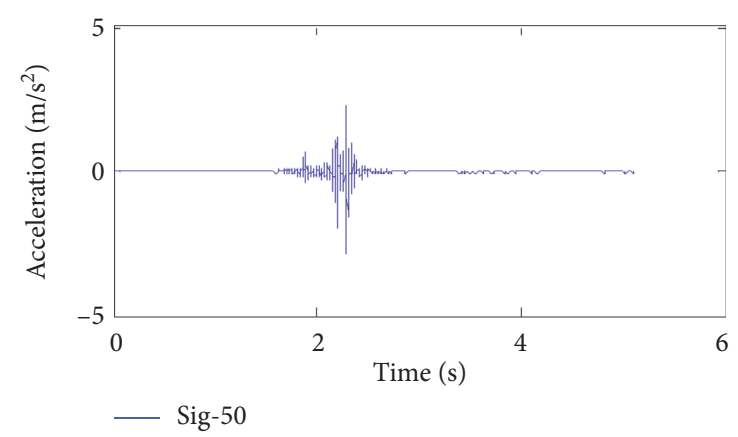

(a)

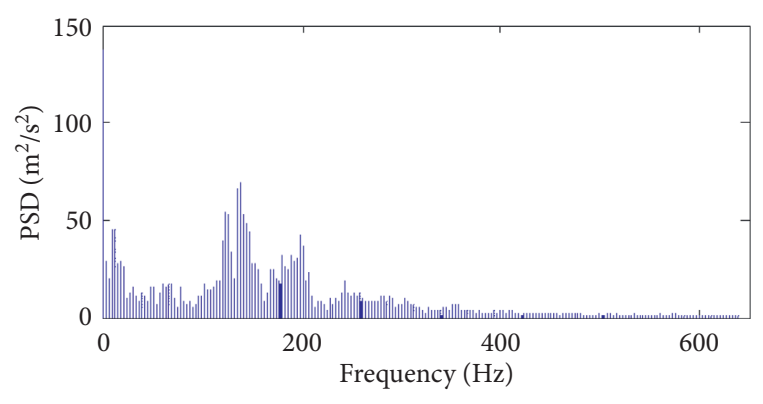

(b)

Figure 8: $50 \mathrm{~cm}$ measuring point signal and power spectral density curve: (a) original signal at $50 \mathrm{~cm}$, and (b) power spectrum curve of $50 \mathrm{~cm}$ signal.

vibration energy is distributed widely in the frequency domain. The holistic transform method adopted in Fourier analysis cannot fully reflect the complex spectrum characteristics of subgrade vibration. The method of frequency division analysis is relatively preferable; that is, it relies on wavelet analysis to decompose the frequency domain and reconstruct test signals to analyze the signal characteristics of different frequency bands.

\subsection{Analysis Method}

4.1.1. Wavelet Theory. The continuous wavelet transform of any function $[f(t)]$ is defined as follows:

$$
W_{f}(a, b)=\left\langle f, \Psi_{a, b}\right\rangle=|a|^{(1 / 2)} \int_{R} f(t) \overline{\Psi\left(\frac{t-b}{a}\right)} \mathrm{d} t,
$$

where $f(t) \in L^{2}(R)$, with $L^{2}(R)$ representing an integrable space with real numbers, that is, a signal space with limited energy. $\Psi_{a, b}$ is the mother wavelet function meeting the allowable conditions. $a$ is the scalability factor, and $b$ is the translation parameters.

To perform wavelet analysis on the computer, the continuous wavelet must be discretized, taking $a=a_{0}^{j}$, $b=k a_{0}^{j} b_{0}, \quad j \in Z$. The corresponding discrete wavelet function $\Psi_{j, t}(t)$ can be written as

$$
\Psi_{j, t}(t)=a_{0}^{-(j / 2)} \Psi\left(\frac{t-k a_{0}^{j} b_{0}}{a_{0}^{j}}\right)=a_{0}^{-(j / 2)} \Psi\left(a_{0}^{-j} t-k b_{0}\right) .
$$
by

The discrete wavelet transform (DWT) can be expressed

$$
\left(f, \Psi_{j, k}\right)=\int_{-\infty}^{+\infty} f(t) \Psi_{j, k}^{\star}(t) \mathrm{d} t .
$$

The high-frequency signal is separated into relatively low frequency and relatively high frequency, and the former part above is processed by using the same method. The rules above should be followed to complete the multilevel signal decomposition. The reconstruction after signal decomposition is shown in

$$
f(t)=c \sum_{j=-\infty}^{\infty} \sum_{k=-\infty}^{\infty} c_{j, k} \Psi_{j, k}(t) .
$$

4.1.2. Frequency Band Processing of Vibration Energy. Taking the measured vertical vibration acceleration under a certain working condition as an example, the processing step of signal frequency bands is as follows:

(i) Taking db3 as the wavelet basis function, the acceleration signal was decomposed to the fifth level, allocated to fifth frequency bands, and then reconstructed. Table 2 lists the frequency ranges of each band.

(ii) The sampling frequency of the original signal was $1280 \mathrm{~Hz}$, and the maximum frequency was $640 \mathrm{~Hz}$. The 4-order DWT was applied to the signal. The frequency band of 1-order specific details (highfrequency $d 1$ ) was $320-640 \mathrm{~Hz}$, and the frequency band of 1-order approximation (low-frequency a1) was less than $320 \mathrm{~Hz}$. The above low-frequency part (a1) was decomposed again. The frequency band of 2-order specific details (high-frequency band $d 2$ ) was $160-320 \mathrm{~Hz}$, and the 2-order approximation (low-frequency band a2) was less than $160 \mathrm{~Hz}$. In accordance with the aforementioned rules, the frequency band of 3-order specific details (highfrequency band $d 3$ ) was $80-160 \mathrm{~Hz}$, and the 3 -order approximation (low-frequency band a3) was less than $80 \mathrm{~Hz}$. The frequency band of 4-order specific details (high-frequency band $d 4$ ) was $40-80 \mathrm{~Hz}$, and the 4-order approximation (low-frequency band $a 4$ ) was less than $40 \mathrm{~Hz} . a 4, d 2, d 3$, and $d 4$ were reconstituted into a new signal. Figure 9 shows the difference and error between the reconstructed signal and the original signal.

(iii) The autospectral density functions of the reconstructed signal with fifth frequency bands were derived separately.

Figure 9 shows that the error of the measuring point is less than $5 \times 10^{-11}$ at a depth of $50 \mathrm{~cm}$, less than $2 \times 10^{-11}$ at a 
TABLE 2: Frequency range of each band and number of wavelet reconstruction layers.

\begin{tabular}{lccccc}
\hline Number of frequency bands & 1 & 2 & 3 & 4 \\
\hline Frequency range $(\mathrm{Hz})$ & $0-40$ & $40-80$ & $80-160$ & $160-320$ & $320-640$ \\
Number of wavelet reconstruction layers & $a 4$ & $d 4$ & $d 3$ & $d 2$ & $d 1$ \\
\hline
\end{tabular}
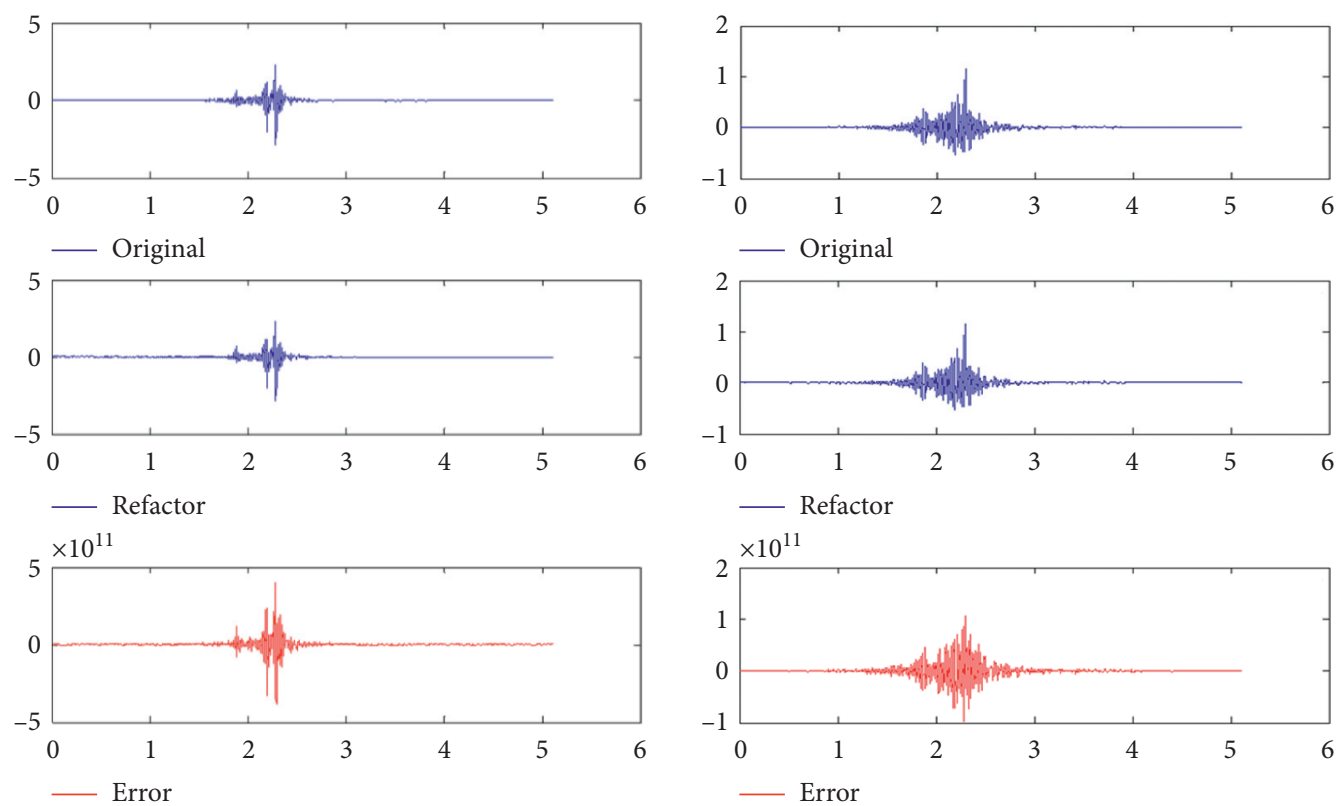

(a)

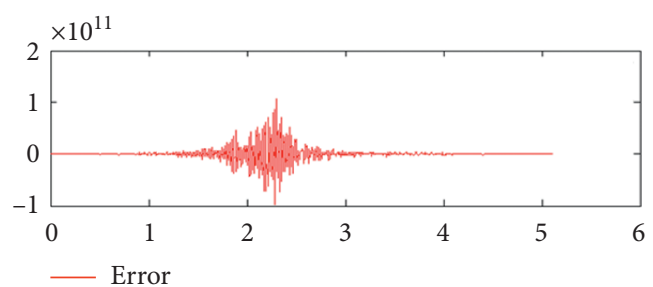

(b)
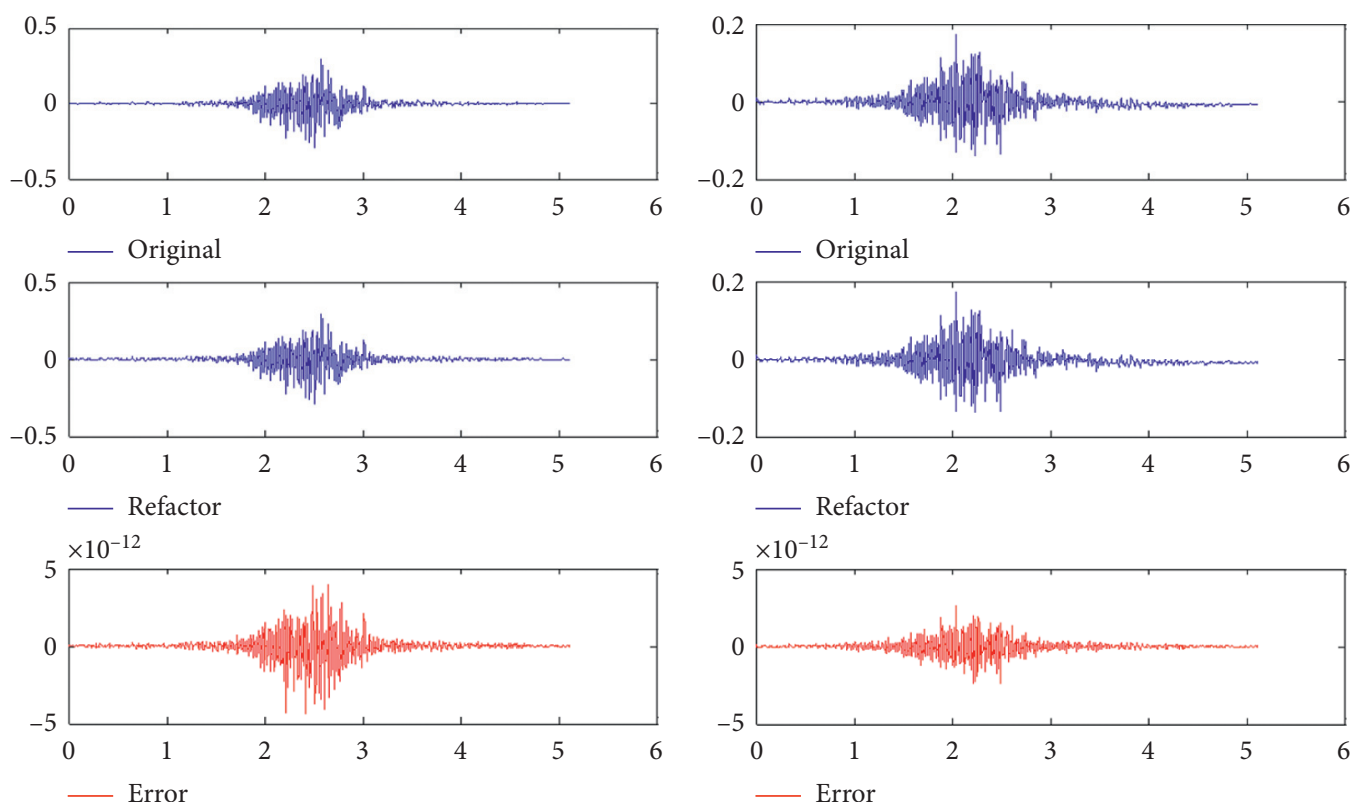

(c)

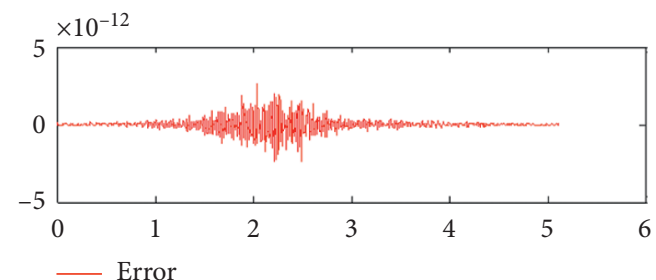

(d)

Figure 9: Comparison and error between the original signal and reconstructed signal: (a) $50 \mathrm{~cm}$, (b) $100 \mathrm{~cm}$, (c) $220 \mathrm{~cm}$, and (d) $350 \mathrm{~cm}$.

depth of $100 \mathrm{~cm}$, and less than $2 \times 10^{-11}$ at a depth of $220 \mathrm{~cm}$ and $350 \mathrm{~cm}$. These results indicate that the analysis method is recommended.

Figure 10 shows the accelerations and power spectrum curves of reconstructed signals on the fifth frequency bands at the $50 \mathrm{~cm}$ depth testing points.
The vibration energy of the above frequency band is decomposed into its frequency range, which is the difference between it and the original signal. MATLAB programming can be used to calculate the average energy of each point on the power spectral density (PSD) curve of each frequency band, so as to compare the vibration energy of each 


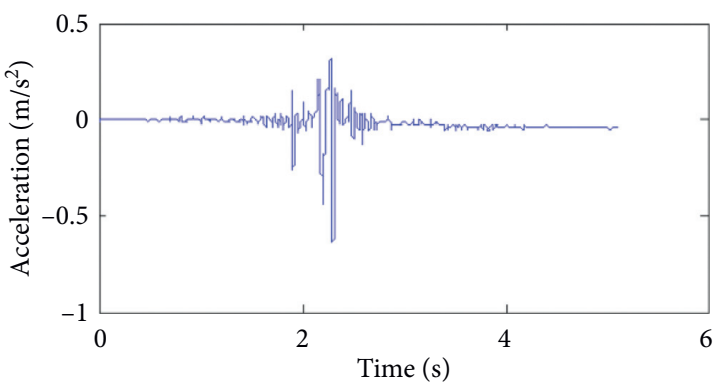

$-(0-40 \mathrm{~Hz})$

(a)

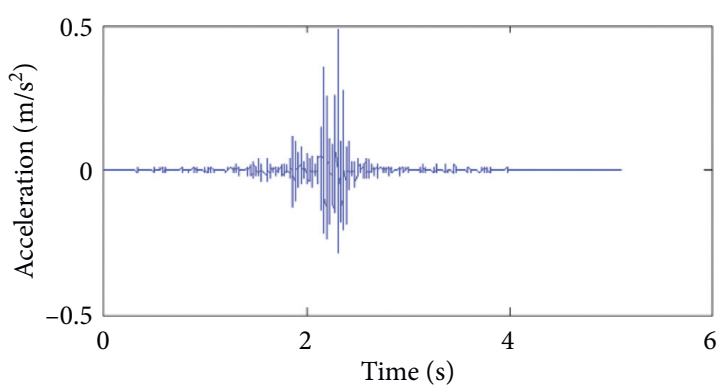

$-(40-80 \mathrm{~Hz})$

(c)

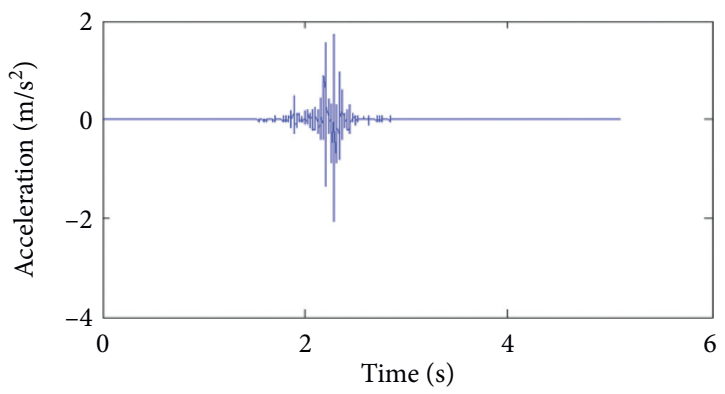

$-(80-160 \mathrm{~Hz})$

(e)

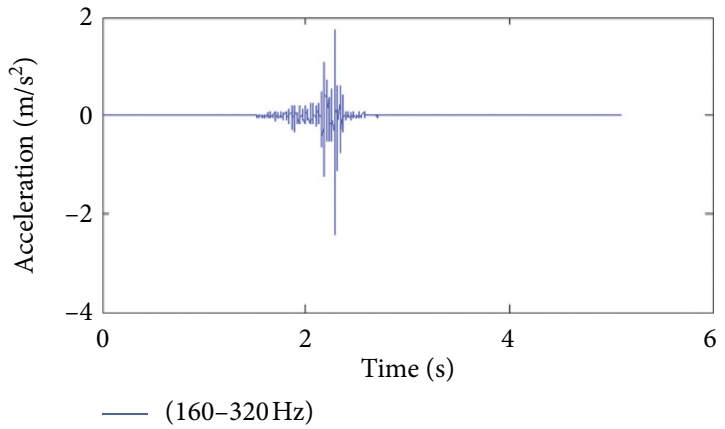

(g)

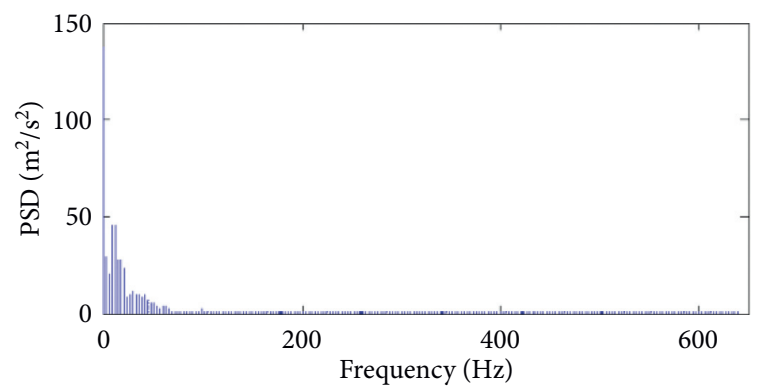

(b)

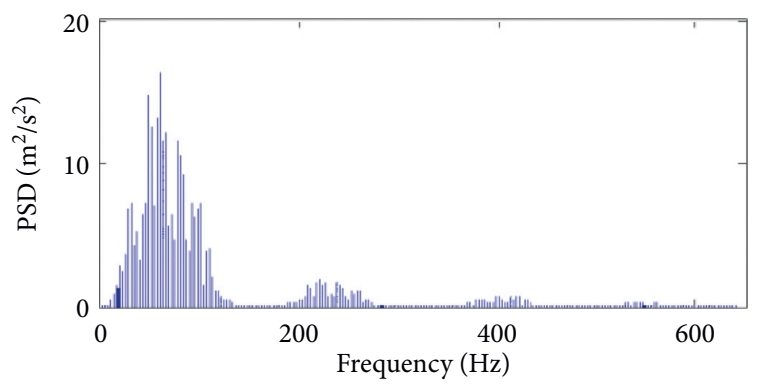

(d)

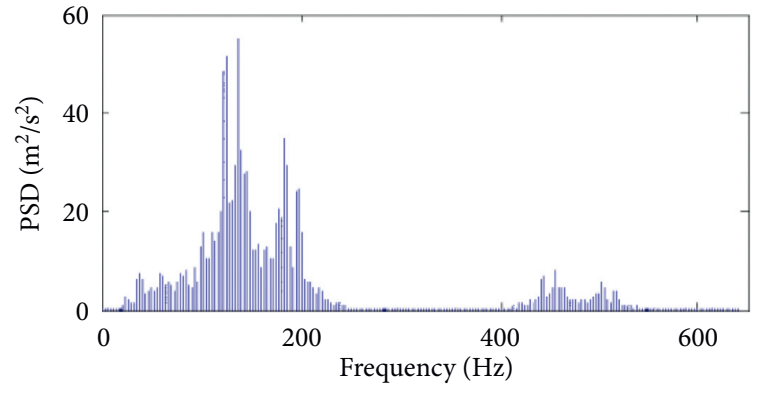

(f)

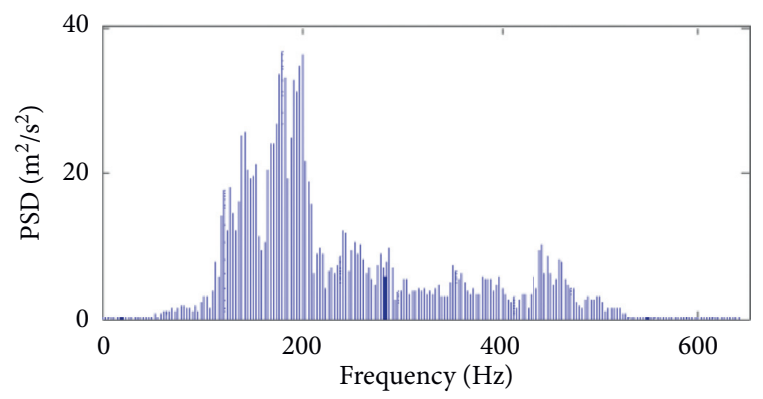

(h)

Figure 10: Continued. 


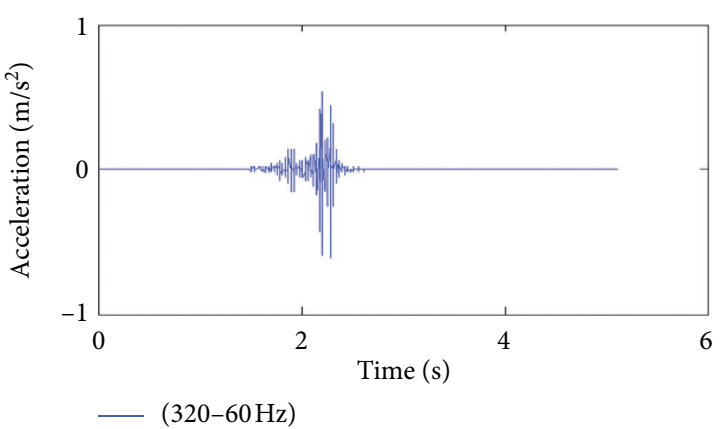

(i)

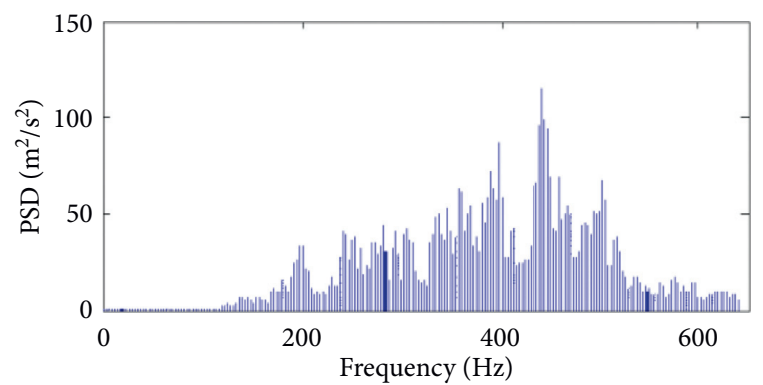

(j)

FIGURE 10: Acceleration and power spectrum curves of reconstructed signals on the fifth frequency bands at the $50 \mathrm{~cm}$ depth testing points: (a) acceleration curve of the first frequency band, (b) power spectrum curve of the first frequency band, (c) acceleration curve of the second frequency band, (d) power spectrum curve of the second frequency band, (e) acceleration curve of the third frequency band, (f) power spectrum curve of the third frequency band, $(\mathrm{g})$ acceleration curve of the fourth frequency band, $(\mathrm{h})$ power spectrum curve of the fourth frequency band, (i) acceleration curve of the fifth frequency band, and ( $j$ ) power spectrum curve of the fifth frequency band.

TABLE 3: Average value of PSD in each frequency band at $50 \mathrm{~cm}$ measuring point.

\begin{tabular}{lcccc}
\hline Number of frequency bands & 1 & 2 & 3 & 4 \\
\hline Frequency range $(\mathrm{Hz})$ & $0-40$ & $40-80$ & $80-160$ & $160-320$ \\
Number of wavelet reconstruction layers & $a 4$ & $d 4$ & $d 3$ & $d 2$ \\
PSD $\left(\mathrm{m}^{2} / \mathrm{s}^{2}\right)$ & 1.2161 & 0.8538 & 3.5504 & 4.4297 \\
\hline
\end{tabular}

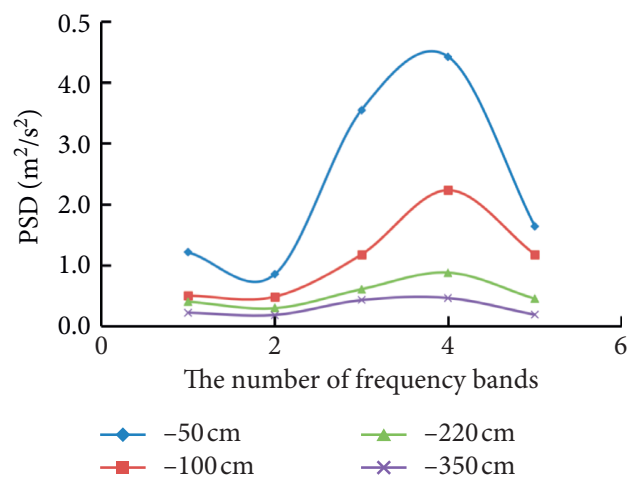

FIgURE 11: Distribution of vibration energy in different frequency bands of the test section.

frequency band. The average energy of each frequency band at the $50 \mathrm{~cm}$ depth testing point is listed in Table 3 . Similarly, the above methods can be used to obtain the relevant information at the testing points of $100 \mathrm{~cm}, 220 \mathrm{~cm}$, and $350 \mathrm{~cm}$ below the road surface.

4.2. Rule of Vibration Energy Distribution of Subgrade. All average values of PSD obtained at the same testing points at the same speed were collected to draw the vibration energy distribution diagram, as presented in Figure 11.

On the whole, vibration energy decreases with the depth of subgrade, which is consistent with the amplitude distribution of vibration acceleration. The vibration energy of the third and fourth frequency bands $(80-320 \mathrm{~Hz})$ is the largest and most sensitive to depth, whereas the vibration energy of the first, second, and fifth frequency bands is lower and their sensitivity to depth is weaker than that of the third and fourth. This result indicates that the attenuation of vibration energy in-depth direction mainly occurs in the 3rd and 4th frequency bands.

4.3. The Influence of Speed on Vibration Energy of Subgrade. After summarizing the vibration energy values at each measuring point, the influence of travel speed on vibration energy at each frequency band is analyzed. Figure 12 statistically illustrates the mean PSD values of frequency bands at each measuring point under three speeds $(20 \mathrm{~km} / \mathrm{s}, 40 \mathrm{~km} /$ $\mathrm{s}$, and $60 \mathrm{~km} / \mathrm{s}$ ).

The vibration energy of each frequency band is sensitive to speed. When the speed increases from $20 \mathrm{~km} / \mathrm{h}$ to $40 \mathrm{~km} /$ $h$, the average PSD of each frequency band increases significantly. Taking the measuring point at a depth of $50 \mathrm{~cm}$ as an example, the PSD values of frequency bands corresponding to a speed of $40 \mathrm{~km} / \mathrm{h}$ increased by $93 \%, 52 \%$, $758 \%, 498 \%$, and $127 \%$ compared with the speed of $20 \mathrm{~km} / \mathrm{h}$. The acceleration of the heavy truck intensifies the vibration of the subgrade. When the velocity is raised from $40 \mathrm{~km} / \mathrm{h}$ to $60 \mathrm{~km} / \mathrm{h}$, the amplification of PSD values is not significant, indicating that the vibration energy evolves slowly at this stage. Conditions at other depths are similar. Moreover, the frequency bands mainly affected by acceleration are the 3rd and 4th frequency bands. The influence of speed on the vibration of subgrade mainly occurs within the range of roadbed and decreases with the depth of subgrade. 


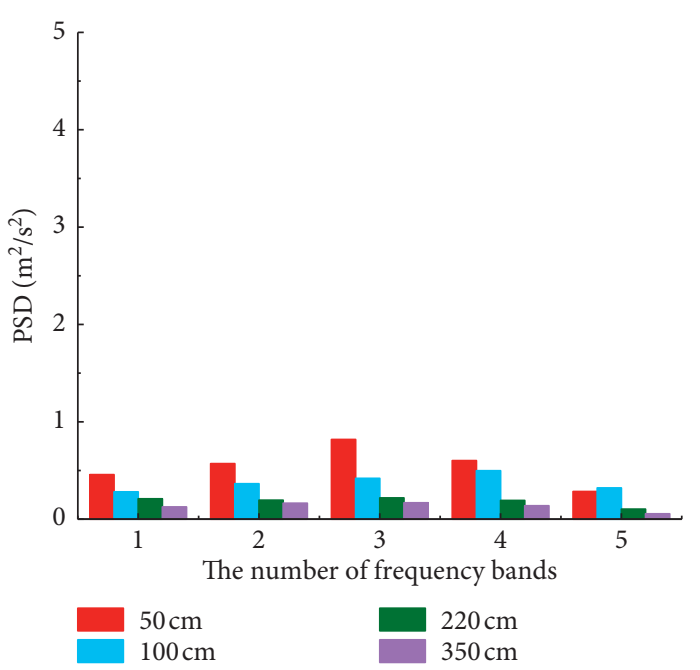

(a)

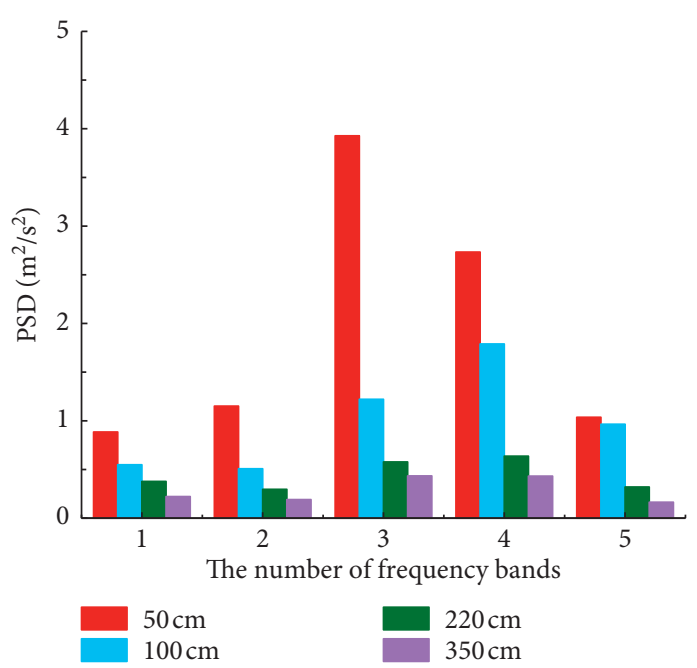

(b)

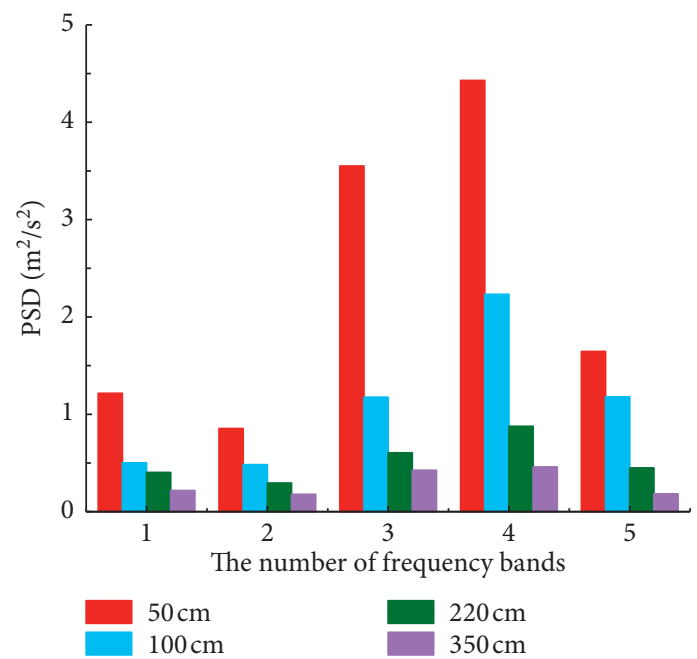

(c)

FIGURE 12: Distribution diagram of the frequency division vibration energy of the test section at various vehicle speeds: (a) $v=20 \mathrm{~km} / \mathrm{h}$, (b) $v=40 \mathrm{~km} / \mathrm{h}$, and (c) $v=60 \mathrm{~km} / \mathrm{h}$.

\section{Conclusions}

This paper quantitatively analyzed the internal dynamic response of lateritic soil subgrade under the action of vehicles with different axial loads and speeds. Moreover, the frequency domain characteristics of the dynamic response of the subgrade were studied through the wavelet analysis. The following conclusions can be drawn.

(1) The additional stress and vibration acceleration caused by vehicles with different speeds and loads passing through the test section decrease with the increase of depth. The dynamic stress and acceleration of each measuring point increase with the increase of speed and load. However, at different depths, the peak values of dynamic stress and acceleration have different development trends with the increase of vehicle speed. This finding presents a nonlinear development trend in the subgrade surface layer and a linear development trend in the deeper layer, especially in acceleration.

(2) Analysis of the frequency domain of the subgrade vibration reveals that vibration energy decays along with the subgrade depth. The vibration energy of the $3 \mathrm{rd}$ and 4 th frequency bands $(80-320 \mathrm{~Hz})$ is the largest and most sensitive to depth change. Therefore, the attenuation of vibration energy indepth direction mainly occurs in these frequency bands.

(3) The vibration of the subgrade is aggravated by the increase of the speed of the heavy-duty truck during construction. Speed has a major influence on the vibration energy of each frequency band; the maximum vibration energy is increased by approximately 7.6 times. In addition, acceleration has the greatest impact on vibration energy in the $3 \mathrm{rd}$ and 4th frequency bands. 


\section{Data Availability}

The data used to support the findings of this study are available from the corresponding author upon request.

\section{Conflicts of Interest}

The authors declare that they have no conflicts of interest.

\section{Acknowledgments}

This research work was funded by the National Natural Science Foundation of China (Grant no. 41772339).

\section{References}

[1] H. Haiying, "The field test and numerical analysis of expressway subgrade dynamic response," Journal of Changsha University of Science \& Technology (Natural Science), vol. 9, no. 2, pp. 13-18, 2012.

[2] P. Galvín, A. Romero, and J. Domínguez, "Vibrations induced by HST passage on ballast and non-ballast tracks," Soil Dynamics and Earthquake Engineering, vol. 30, no. 9, pp. 862873, 2010.

[3] D. Connolly, A. Giannopoulos, and M. C. Forde, "Numerical modelling of ground borne vibrations from high speed rail lines on embankments," Soil Dynamics and Earthquake Engineering, vol. 46, pp. 13-19, 2013.

[4] Y. Shan, B. Albers, and S. A. Savidis, "Influence of different transition zones on the dynamic response of track-subgrade systems," Computers and Geotechnics, vol. 48, pp. 21-28, 2013.

[5] Y. J. Shan, Y. Shu, and S. Zhou, "Finite-infinite element coupled analysis on the influence of material parameters on the dynamic properties of transition zones," Construction and Building Materials, vol. 148, pp. 48-558, 2017.

[6] G. Degrande and L. Schillemans, "Free field vibrations during the passage of a thalys high-speed train at variable speed," Journal of Sound and Vibration, vol. 247, no. 1, pp. 131-144, 2001.

[7] N. C. D. Santos, A. Colaço, P. A. Costa, and R. Calçada, "Experimental analysis of track-ground vibrations on a stretch of the Portuguese railway network," Soil Dynamics and Earthquake Engineering, vol. 90, pp. 358-380, 2016.

[8] P. Galvín and J. Domínguez, "Experimental and numerical analyses of vibrations induced by high-speed trains on the Córdoba-Málaga line," Soil Dynamics and Earthquake Engineering, vol. 29, no. 4, pp. 641-657, 2009.

[9] L. Xue-zu and C. Guo-xing, "Advances in researches on mechanical behavior of subgrade soils under repeated-load of high-speed track vehicles," Journal of Disaster Prevention and Mitigation Engineering, vol. 28, no. 2, pp. 248-255, 2008.

[10] N. Ru-song, M. Hui-hao, L. Wu-ming et al., "Experimental research on dynamic response characteristics of transition subgrade induced by heavy-haul trains," China Civil Engineering Journal, vol. 52, no. 5, pp. 101-115, 2019.

[11] M. Hyodo and K. Yasuhara, "Analytical procedure for evaluating pore-water pressure and deformation of saturated clay ground subjected to traffic loads," in Proceedings of the Sixth International Conference on Numerical Methods in Geomechanics, Innsbruck, Austria, April 1988.

[12] W. Xuan, Z. Jia-sheng, Y. Guo-yue, and C. Xiao-bin, "Test on dynamic stress of roadbed and pavement uner heavy loads," Journal of Vibration and Shock, vol. 26, no. 6, pp. 169-173+192, 2007.
[13] T. V. McEwen, A. L. Priest, and D. H. Timm, "Design and instrumentation of the structural pavement experiment at the NCAT test track," NCAT Report 04-01, National Center for Asphalt Technology, Auburn, AL, USA, 2004.

[14] C. Yu, X. Lin-rong, L. Wei zheng, S. Yong hui, S. Na, and F. Duo, "Field test study on the dynamic response of the cement-improved expansive soil subgrade of a heavy-haul railway," Soil Dynamics and Earthquake Engineering, vol. 128, p. 105878, 2020.

[15] X. Junhua, W. Binglong, L. Chengyu, and Y. Zheng, "Influences of subgrade form and ground stiffness on dynamic responses of railway subgrade under train loading: field testing case study," Procedia Engineering, vol. 143, pp. 1185$1192,2016$.

[16] D. P. Connolly, P. Alves Costa, G. Kouroussis, P. Galvin, P. K. Woodward, and O. Laghrouche, "Large scale international testing of railway ground vibrations across Europe," Soil Dynamics and Earthquake Engineering, vol. 71, pp. 1-12, 2015.

[17] C. A. Ribeiro, C. Rui, and R. Delgado, "Experiment alassessment of the dynamic behaviour of the train-track system at a culvert transition zone," Engineering Structures, vol. 138, pp. 215-228, 2017.

[18] D. P. Connolly, G. Kouroussis, P. K. Woodward, P. Alves Costa, O. Verlinden, and M. C. Forde, "Field testing and analysis of high speed rail vibrations," Soil Dynamics and Earthquake Engineering, vol. 67, pp. 102-118, 2014.

[19] Z. Xiong-fei and C. KaiSheng, "Study on the swell \& shrinking deformation characteristics of red clay under the condition of dry-wet circulation," Journal of Guizhou University (Natural Sciences), vol. 33, no. 1, pp. 132-135, 2016.

[20] H. Yong-qiang, T. Lian-sheng, and L. Pei-yuan, "Analysis of dynamic characteristics of subgrade red clays in Southern China using dynamic triaxial tests," Journal of Natural Disasters, vol. 27, no. 6, pp. 13-18, 2018.

[21] L. Shuang, "In-situ dynamic experimental study for simulating dynamic response of subgrades," Chinese Journal of Rock Mechanics and Engineering, vol. 39, no. 32020, pp. 629-636, 2020.

[22] L. Ze-feng, Q. Jin-song, L. Jian-ming, and C. Yang, "Dynamic response of heavy-duty asphalt pavement affected by moisture," Journal of Tongji University (Natural Science), vol. 44, no. 5, pp. 734-739, 2016. 